Brit. J. industr. Med., 1953, 10, 18.

\title{
SOME PSYCHOLOGICAL CONFLICTS CAUSED BY GROUP BONUS METHODS OF PAYMENT
}

\author{
BY \\ NORAH M. DAVIS \\ From the Medical Research Council Group for Research in Industrial Psychology, \\ University College, London
}

(RECEIVED FOR PUBLICATION JULY 31,1952 )

The need for a high level of industrial output has given rise in recent years to a widespread discussion on wage incentives. Although no statistics exist showing the total number of workers in British industry who are paid by results, such figures as the Ministry of Labour has been able to collect indicate that the number is increasing. In October, 1951, just over a third of the workers at the 56,200 industrial establishments surveyed by the Ministry were paid on some system of payment by results, and in nearly all groups of industries the percentage of workers was higher than it had been in October, 1949 (Ministry of Labour Gazette, 1952). In a pamphlet giving the results of the 1949 inquiry the Ministry of Labour and National Service (1951) stated that wage incentive schemes, if well designed and suitable, "will benefit the nation as a whole and give mutual advantage and satisfaction to the employers and workers concerned" and advocated "a more general adoption" of such schemes. Thus official encouragement is now being given to the use of such schemes. This article presents some results of recent researches which indicate not only the difficulties of applying incentive payment to many industrial processes but also the often harmful effects on the morale and possibly on the health of the workers.

Many claims have been made that wage incentive schemes lead to increased production, but attempts to secure reliable evidence on this point have usually met with failure, since in practice it has proved impossible to isolate the effects of the "incentive" from those of other factors. For example, as the International Labour Office (1951) among others has pointed out, a subsequent rise in production may be largely due to "the work study which is required to enable a system of payment by results to function smoothly and successfully". Many other variables also make it difficult to establish a causal as distinct from a temporal relationship. The aim of this article, however, is not to discuss bonus systems in general or to examine them in relation to their effect on production, but to summarize some of the main results of an inquiry into the attitudes of certain groups of industrial workers towards their group bonus methods of payment. Few scientific studies have yet been made of workers' attitudes to their systems of payment, nor has detailed consideration been given to the psychological effects of such schemes. The International Labour Office report already quoted mentions the danger that "if the task is set too high, or there is a low guaranteed minimum wage, the health, efficiency and morale of the workers may be adversely affected" (p. 178). As the following results will show, the task set and the wage guaranteed are only two of the many factors which may have these undesirable effects.

It is only by considering a system of payment from the point of view of the workers concerned that any appraisal can be made of the causes and nature of their reactions to it. The effectiveness of any external stimulus or " incentive " must depend very largely on the potential strength of the drives to action to which it is directed. Without some understanding of the motives and "ends" of the workers it is impossible to say how far a wage incentive provides stimulus and satisfaction. There are clearly great individual differences in the strength and constancy of the desire for money and there are differences also in the drives to attain other means to satisfaction. Workers' judgments of their systems, and even of their amounts, of payment are relative, not absolute, and the standards by which they estimate "good" and " bad" are still imperfectly known. It seems, however, that their attitude to their system of payment is largely, perhaps 
mainly, determined by the degree to which the behaviour induced by the effort to earn more money conflicts or harmonizes with behaviour directed to other ends. If opposing drives are strong enough they may result not only in the workers' refusal to respond to the financial incentive but in a definite restriction of output. But whatever the outcome in terms of production, the conflicts tend to arouse feelings of anxiety and frustration that are manifested in a variety of psychological and physical symptoms.

Since both psychological and, to some extent, physiological factors are involved in the problem of methods of payment, it would seem that these are, or might profitably be considered, the concern of the factory medical officer as well as of the " production expert" and the management. It is not the "wage earner" but the whole man who goes to work, and the closeness of the relation between mental attitudes and physical health is becoming increasingly realized. Cases have come to the notice of the present investigator in which workers complaining of symptoms of fatigue and strain, which they attributed to working "on bonus", have refused to consult their factory medical officer for fear that he would put them on a fixed wage job. The drop in the weekly wage that this change would entail would mean that one source of anxiety would be replaced by another and even more acute source. Apparently it did not occur either to these workers or to the medical officer that the latter might consider it within his duties to re-examine the payment system and possibly advise changes in the system rather than in the jobs of the workers. Lane (1936) has pointed out that in dangerous industries a system of payment which encourages "speedingup " may greatly increase the number of cases of industrial disease. Even in industries which involve no serious hazards to health, however, the medical officer might do much to improve the general wellbeing and morale of the workers if he advised on the planning of systems of payment and supervised the workers in relation to them.

\section{Scope of the Investigation}

The inquiries from which the material here presented was gathered were made in the periods March, 1948, to March, 1949, and June, 1950, to April, 1951. The inquiries were undertaken for a variety of reasons but in all cases each worker involved was given a general interview covering all the main aspects of working life, including amounts and methods of payment. Only those workers who were paid on a group bonus system (386 men and 402 women) are dealt with in this article. In each factory the workers selected were either the total number on a particular operation or were a statistically random sample of a department or factory. Each worker was interviewed singly and in private, and was given an assurance that the interview would be regarded as confidential. It is not possible to give particulars here of the interviewing technique used. Briefly, this consisted of using both the "free" and the "controlled " methods in the same interview so that the person interviewed was encouraged both to talk spontaneously and also to answer certain pre-determined questions. Various devices were used to prevent or correct interviewer-bias. The interviews were voluntary but almost all the workers cooperated willingly and talked extremely frankly and fully. The percentage of refusals was $0 \cdot 4$, except in one department of about 90 workers where it was $10 \%$, mainly owing to a rumour which could not be entirely dispelled that the investigators were psychiatrists. In all cases both the managements and the workers' representatives had approved the investigations and helped to facilitate them. The fact that the investigators were outsiders, from an independent research organization, helped to establish confidence and it is of some interest that the workers often showed themselves not only willing but eager to assist in a scientific inquiry from which they were told to expect no immediate and personal benefits. During the interviews the workers gave in some detail their reasons for liking or disliking the system of payment and finally were asked to assess their attitude to it on a five-point rating scale.

The workers were employed in five factories, in three of which a variety of articles were manufactured or processed. The main types of work carried out by the men were the making of parts of pre-fabricated concrete houses, engineering and building maintenance and repair work, the making or disposal of miscellaneous military equipment (details of which cannot be given here), and cigarette manufacture. Women were also engaged on the two latter types of work as well as on making clothing and pottery. The numbers in a payment group varied considerably, ranging from two, e.g., the operator and his woman assistant on a cigarettemaking machine, to about 180 , e.g., the total number in a department making pre-fabricated houses. All the workers were paid a fixed hourly rate and a bonus based on the relation of actual to expected time (determined by time-study) for the work done. The bonus of the maintenance workers was reckoned partly on their own work and partly on the total production of the factory. 
TABLE 1

ASSESSMENTS OF ATTITUDES TO THE GROUP BONUS SYSTEM

\begin{tabular}{|c|c|c|c|c|c|c|c|c|c|c|c|c|c|c|}
\hline \multicolumn{5}{|c|}{ (a) Men } & \multicolumn{2}{|c|}{$\begin{array}{l}\text { Prefabricated } \\
\text { Houses }\end{array}$} & \multicolumn{2}{|c|}{$\begin{array}{c}\text { Military } \\
\text { Equipment }\end{array}$} & \multicolumn{2}{|c|}{$\begin{array}{c}\text { Factory } \\
\text { Maintenance }\end{array}$} & \multicolumn{2}{|c|}{ Cigarettes } & \multicolumn{2}{|c|}{ Total } \\
\hline & & & & & No. & $\%$ & No. & $\%$ & No. & $\%$ & No. & $\%$ & No. & $\%$ \\
\hline $\begin{array}{l}\text { Extremely satisfied } \\
\text { Satisfied } \\
\text { Neutral or divided } \\
\text { Dissatisfied } \\
\text { Extremely dissatisfied }\end{array}$ & $\begin{array}{l}\cdots \\
\cdots \\
\dot{d}\end{array}$ & $\begin{array}{l}\cdots \\
\cdots \\
\cdots\end{array}$ & $\begin{array}{l} \\
\cdots \\
\cdots \\
\cdots \\
\therefore\end{array}$ & $\begin{array}{l}\ldots \\
\cdots \\
\cdots\end{array}$ & $\begin{array}{r}2 \\
37 \\
25 \\
14 \\
1\end{array}$ & $\begin{array}{r}2 \cdot 5 \\
46 \cdot 8 \\
31 \cdot 6 \\
17 \cdot 7 \\
1 \cdot 3\end{array}$ & $\begin{array}{r}0 \\
25 \\
42 \\
33 \\
8\end{array}$ & $\begin{array}{r}0 \cdot 0 \\
23 \cdot 1 \\
38 \cdot 9 \\
30 \cdot 6 \\
7 \cdot 4\end{array}$ & $\begin{array}{r}4 \\
18 \\
42 \\
14 \\
4\end{array}$ & $\begin{array}{r}4 \cdot 9 \\
22 \cdot 0 \\
51 \cdot 2 \\
17 \cdot 1 \\
4 \cdot 9\end{array}$ & $\begin{array}{r}8 \\
24 \\
34 \\
23 \\
28\end{array}$ & $\begin{array}{r}6 \cdot 8 \\
20 \cdot 5 \\
29 \cdot 1 \\
19 \cdot 7 \\
23 \cdot 9\end{array}$ & $\begin{array}{r}14 \\
104 \\
143 \\
84 \\
41\end{array}$ & $\begin{array}{r}3 \cdot 6 \\
26.9 \\
37 \cdot 0 \\
21 \cdot 8 \\
10 \cdot 6\end{array}$ \\
\hline \multirow[t]{2}{*}{ (b) } & \multirow{2}{*}{\multicolumn{2}{|c|}{ Women }} & & & \multicolumn{2}{|c|}{ Clothing } & \multicolumn{2}{|c|}{$\begin{array}{c}\text { Military } \\
\text { Equipment }\end{array}$} & \multicolumn{2}{|c|}{ Pottery } & \multicolumn{2}{|c|}{ Cigarettes } & \multicolumn{2}{|c|}{ Total } \\
\hline & & & & & No. & $\%$ & No. & $\%$ & No. & $\%$ & No. & $\%$ & No. & $\%$ \\
\hline $\begin{array}{l}\text { Extremely satisfied } \\
\text { Satisfied } \\
\text { Neutral or divided } \\
\text { Dissatisfied . } \\
\text { Extremely dissatisfied }\end{array}$ & $\begin{array}{l}\cdots \\
\cdots \\
\dot{d}\end{array}$ & $\begin{array}{l}\ldots \\
\cdots \\
\cdots\end{array}$ & $\begin{array}{l}\cdots \\
\cdots \\
\cdots \\
\cdots\end{array}$ & $\begin{array}{l}\cdots \\
\cdots \\
\cdots \\
\cdots\end{array}$ & $\begin{array}{r}0 \\
27 \\
27 \\
24 \\
0\end{array}$ & $\begin{array}{r}0.0 \\
34.6 \\
34.6 \\
30.8 \\
0.0\end{array}$ & $\begin{array}{r}0 \\
11 \\
14 \\
17 \\
8\end{array}$ & $\begin{array}{r}0.0 \\
22.0 \\
28.0 \\
34.0 \\
16.0\end{array}$ & $\begin{array}{r}0 \\
2 \\
5 \\
16 \\
0\end{array}$ & $\begin{array}{r}0.0 \\
8.7 \\
21.7 \\
69.6 \\
0.0\end{array}$ & $\begin{array}{r}4 \\
84 \\
89 \\
62 \\
12\end{array}$ & $\begin{array}{r}1.6 \\
33.5 \\
35.5 \\
24.7 \\
4.8\end{array}$ & $\begin{array}{r}4 \\
124 \\
135 \\
119 \\
20\end{array}$ & $\begin{array}{r}1.0 \\
30.8 \\
33.6 \\
29.6 \\
5.0\end{array}$ \\
\hline Totals & $\ldots$ & . & $\ldots$ & . & 78 & $100 \cdot 0$ & 50 & $100 \cdot 0$ & 23 & $100 \cdot 0$ & 251 & $100 \cdot 1$ & 402 & $100 \cdot 0$ \\
\hline
\end{tabular}

\section{Some Results Obtained}

Self-Assessments of General Attitudes to Method of Payment.-Table 1 shows the self-assessments, on a five-point rating scale, by the workers of their general attitude to their system of payment. It will be seen that the figures for the total numbers of men and women are very similar, about a third being extremely or moderately satisfied, a third being divided or neutral in attitude, and a third being dissatisfied. There are naturally differences between persons on different types of work, and a finer breakdown would show even greater differences, but it may be noted that the highest figure for satisfaction among the men is only $49.3 \%$ (pre-fabricated houses). In this particular instance it should be said that in one of the two factories concerned (employing 40 of the 79 men in this group) the men were able to earn an exceptionally high bonus, more than twice as much as any worker in other departments of the same factory. The outstanding difference among the women, although this was a small group, was the high proportion of pottery workers who were dissatisfied. This is an instance of the effect of introducing a bonus system into a newly-opened department in which methods of working were still largely experimental and in which both the supervisors and the workers were not experienced. Despite differences between different groups of workers, however, both the favourable and the unfavourable comments made were fundamentally very similar even if the frequency or emphasis varied. Even a broad analysis of these comments indicates not only some of the sources of strain but also the positive goals which the workers desire to reach.
Favourable Comments on Group Bonus System of Payment.-Since the main subject of this article is the conflicts arising from the bonus system of payment, the favourable comments will be mentioned only briefly. It should, however, be said that reasons for liking the system were given by the majority of both men $(73 \cdot 1 \%)$ and women $(67 \cdot 2 \%)$, including many of those whose general attitude was unfavourable. A considerable minority, about a fifth of both men and women, stated emphatically that they liked nothing whatever about the system. Two types of comment accounted for nearly all the favourable remarks and were made with almost equal frequency. First, some workers spoke of the personal satisfaction of having an opportunity to earn more money. However, many of these workers qualified their statements by saying that without the bonus payment they did not earn an adequate living wage. As one man said, "I only like it because it makes your wages up. Without bonus the wages are not enough to cover costs and it's dreadful for a married man rearing children." Secondly, some spoke of the social advantages of group bonus methods of payment, saying that it encouraged everyone to work and do a fair share. A typical comment was, "It makes everyone more amicable. This way you have no strong men and weak men but each man works to his own capacity and earns a full bonus." The implication of the above remark is that it is just to reward a man according to his willingness rather than according to his performance. It is a different attitude from that of the much smaller group (7.5\% of men and $9.0 \%$ of women) who said that it was " fair to be paid for what you do". However the relative infrequency of the 
latter comment may have been partly due to the fact, to be discussed later, that very few workers were able to see any clear relation between effort and reward.

The amount of the average weekly wage, including bonus earnings, affected the general attitude of the workers to the system of payment, those who were satisfied with their wage tending to be less critical of the method by which they had obtained it. However, although there were variations according to type of work, both men and women were far more satisfied with amounts than with methods of payment. Only a small minority of the total men and women $(11.7 \%$ and $16.2 \%)$ thought that their his own rate of working or from receiving an understandable and commensurate reward. Secondly, a conflict might arise between the desire of the individual or the group to earn bonus and the desire to maintain or create good social relationships. And thirdly, the individual might find that the behaviour induced in himself by the effort to reach or exceed his target was at variance with his personal standards of health and conduct.

The number of workers who criticized their system of payment on one or more of these three grounds, together with the number who had no complaint, is shown in Table 2 .

Table 2 shows that even in the most satisfied

TABLE 2

NUMBER OF PERSONS EXPRESSING THREE TYPES OF CONFLICT ARISING FROM THE GROUP BONUS SYSTEM

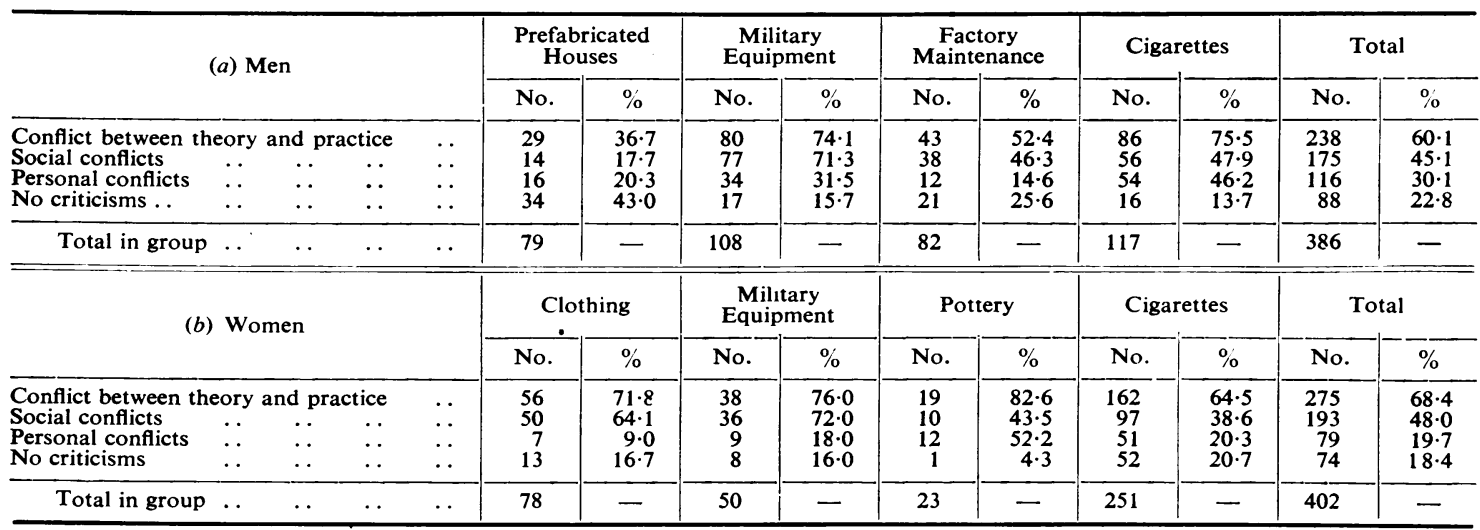

wages were poor, although far larger proportions $(32 \cdot 4 \%$ and $34.6 \%)$ were definitely dissatisfied with their system of payment. One factor determining a worker to call his wages "medium" rather than "good" was the unpredictable fluctuations of the bonus, commented on in this connexion by $17.5 \%$ of men and $22.7 \%$ of women.

Unfavourable Comments on Group Bonus System of Payment.-Adverse comments were made by $77.2 \%$ of the men and $81.6 \%$ of the women, including some of those who assessed their general attitude in one of the two top categories of the rating scale. These comments were very varied but all the specific and sometimes very localized grievances they expressed may be regarded as indications of three main types of psychological conflict. The most frequent conflict may be termed that between expectation and result, or between theory and practice; this arose when the worker was prevented, by causes apparently or actually largely outside his control, either from determining group of workers (the men making prefabricated houses) a majority made adverse comments, of which the most frequent were those indicating the discrepancy between theory and practice. There are differences, as would be expected, between the groups and between the sexes, but a full discussion of these would involve giving details of local circumstances for which space is not here available. Some examples will be mentioned later.

A broad analysis of the comments which have been grouped into these three categories is made in Table 3, which shows the frequency of the main types of criticism within each category.

Conflict between Theory and Practice.-Criticisms considered to reflect this type of conflict were made by $60.1 \%$ of the men and $68.4 \%$ of the women and accounted for just over half of the total number of critical comments. The most frequent group of comments included in this category referred to the apparent lack of connexion between bonus earnings and effort. Many worke felt

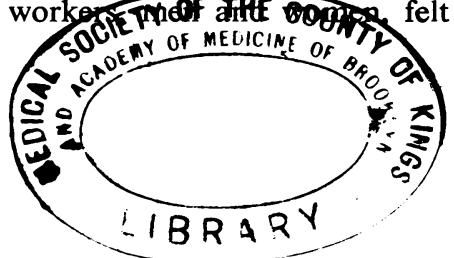


TABLE 3

NUMBER OF WORKERS MAKING CRITICISMS* REVEALING EACH TYPE OF CONFLICT ARISING FROM GROUP BONUS SYSTEM

\begin{tabular}{|c|c|c|c|c|c|c|c|c|}
\hline & & & \multicolumn{2}{|c|}{ Men } & \multicolumn{2}{|c|}{ Women } & \multicolumn{2}{|c|}{ Total } \\
\hline & & & No. & $\%$ & No. & $\%$ & No. & $\%$ \\
\hline $\begin{array}{l}\text { Conflict between theory and practice } \\
\text { Bonus apparently not related to effort } \\
\text { Timing or rate-fixing unjust } \\
\text { Management unreliable or suspect.. }\end{array}$ & $\begin{array}{l}\cdots \\
\cdots \\
\cdots\end{array}$ & $\begin{array}{l}\ddot{*} \\
\cdots \\
\cdots\end{array}$ & $\begin{array}{r}2.38 \\
151 \\
116 \\
52\end{array}$ & $\begin{array}{r}60 \cdot 1 \\
39 \cdot 1 \\
30 \cdot 1 \\
13 \cdot 5\end{array}$ & $\begin{array}{r}275 \\
191 \\
156 \\
66\end{array}$ & $\begin{array}{r}68 \cdot 4 \\
47 \cdot 5 \\
38 \cdot 8 \\
16 \cdot 4\end{array}$ & $\begin{array}{r}513 \\
342 \\
272 \\
118\end{array}$ & $\begin{array}{r}6.5 \cdot 1 \\
43 \cdot 4 \\
34 \cdot 5 \\
15 \cdot 0\end{array}$ \\
\hline 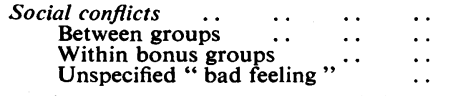 & $\begin{array}{l}\cdots \\
\cdots \\
\cdots\end{array}$ & $\begin{array}{l}\cdots \\
\cdots \\
\cdots\end{array}$ & $\begin{array}{r}175 \\
123 \\
62 \\
11\end{array}$ & $\begin{array}{r}45 \cdot 1 \\
31 \cdot 9 \\
16 \cdot 1 \\
2 \cdot 8\end{array}$ & $\begin{array}{r}193 \\
101 \\
113 \\
16\end{array}$ & $\begin{array}{r}48 \cdot 0 \\
25 \cdot 1 \\
28 \cdot 1 \\
4 \cdot 0\end{array}$ & $\begin{array}{r}368 \\
224 \\
175 \\
27\end{array}$ & $\begin{array}{r}46 \cdot 7 \\
28 \cdot 4 \\
22 \cdot 2 \\
3 \cdot 4\end{array}$ \\
\hline $\begin{array}{l}\text { Personal conflicts } \\
\text { With concern for health and safety } \\
\text { With own code of behaviour }\end{array}$ & $\begin{array}{l}\cdots \\
\cdots \\
\cdots\end{array}$ & $\begin{array}{l}\cdots \\
\cdots \\
\cdots\end{array}$ & $\begin{array}{r}116 \\
74 \\
61 \\
\end{array}$ & $\begin{array}{r}30 \cdot 1 \\
19 \cdot 2 \\
15 \cdot 8 \\
\end{array}$ & $\begin{array}{r}79 \\
46 \\
44 \\
\end{array}$ & $\begin{array}{r}19 \cdot 7 \\
11 \cdot 4 \\
10 \cdot 9 \\
\end{array}$ & $\begin{array}{r}195 \\
120 \\
105\end{array}$ & $\begin{array}{r}24 \cdot 7 \\
15 \cdot 2 \\
13 \cdot 3 \\
\end{array}$ \\
\hline $\begin{array}{l}\text { Total number of persons making criticisms } \\
\text { Total number in group } \ldots\end{array}$ & $\cdots$ & $\begin{array}{l}\cdots \\
\cdots\end{array}$ & $\begin{array}{l}298 \\
386\end{array}$ & $\begin{array}{c}77 \cdot 2 \\
-\end{array}$ & $\begin{array}{l}328 \\
402\end{array}$ & $\stackrel{81 \cdot 6}{-}$ & $\begin{array}{l}626 \\
788\end{array}$ & $\begin{array}{c}79 \cdot 4 \\
-\end{array}$ \\
\hline
\end{tabular}

* Many workers made more than one criticism in each category.

both irritated and anxious at the fluctuations in their weekly wage. In some cases these fluctuations were, in fact, large enough to have a considerable effect on the household budget (and occasionally led to trouble between men workers and their wives).* However, complaints of the unpredictability of the bonus were often more vehement and frequent than the actual variations in amounts earned seemed to warrant and they often seemed to arise from a feeling that the assumed basic principle of " payment by results" was, or appeared to be, violated in practice. In theory, the system should give them rewards proportionate to their efforts but in practice their earnings often seemed to bear little relation to effort or even to output and seemed determined by factors that were outside their control and often only dimly understood. From workers on many types of jobs came complaints that "the bonus just goes up and down and you never know why" and "It's just luck. There's no sense in it". In such workers the bonus system aroused a sense of injustice or of helpless bewilderment ; as one man put it, "It gives you neither uplift or cover".

There were many and varied reasons why so many workers found it impossible to see a clear relation between effort and reward. The constant changes of jobs, some of which carried no bonus at all, in the military equipment departments, were an obvious and outstanding example. However, even on jobs

\footnotetext{
* In one military equipment department the records of the 27 men interviewed showed that in an eight-week period 16 of them received no bonus at all in at least one week, that bonus earnings ranged no bonus at all in at least one week, that bonus earnings ranged
from $2 s .4 d$. to $£ 114 s$. $0 d$. and that for 10 of the men the fluctuations were $£ 1$ or more during the period. In a tobacco department, where were $f 1$ or more during the period. In a tobacco department, wher machine operators ranged from $7 s .9 d$. to $£ 17 s$. 9d. in a 12-week period, although for 15 of the men the fluctuations in their weekly wage were not greater than $15 s$. In both cases the causes of the large differences in earnings were, according to the supervisors, mainly due to the variations in required production dictated by external conditions over which they themselves had no control.
}

where the workers were continuously employed and the flow of work fairly steady, estimation of the bonus to be expected was complicated by numerous factors, such as the various allowances (for machine breakdowns, etc.), the changes in quality of materials, and changes in the composition and size of the group. On one such job a woman said, "We get allowances for breakdowns and things, but we never know exactly how much. And then they take off for rejects. I think you ought to know how much work you've done and what you'll be paid for it but nobody bothers to explain. I don't like the bonus at all, but, to be honest, I might like it better if I understood it."

Another type of situation in which some workers felt that their own capabilities and intentions had little effect on their earnings was that in which the amount of work that it was possible to do was controlled by outside circumstances. For example, on some jobs the amount of material allocated to the workers was determined by production planning, which itself was closely and immediately dependent on orders received by the firm. In one tobacco factory the fluctuations of an individual worker's bonus would reflect the seasonal variations in the demand for cigarettes. On other jobs the work available was determined by the output of workers on a preceding operation or by the requirements of workers who had to be serviced. One man, for instance, whose task was to feed material into a group of machines, said, "The basis of bonus is supposed to be incentive. But we have none because we rely on others. We have no control as they reckon our bonus on the number of machines that are running." Differences in bonus earnings between two groups, one dependent on the other for the amount of work supplied to them, sometimes caused 
very bitter feeling, as shown by the woman tobacco worker who said, "The bonus is the most abhorrent thing that ever came out. It puts all the workers against each other because different groups get different bonus even if they handle the same work. There's no justice in it at all."

Another kind of limitation on human effort and speed of working was that set by the fixed pace of a machine or process. For instance, the operators on cigarette-making machines could affect their bonus only by ensuring that machine faults were not leading to spoiled work or by forestalling or shortening machine stoppages. The main reason for machine stoppages was minor breakdowns or need for adjustments, and as it was at such times only that much demand was made on the skill and judgment of the operators, many of them felt that the bonus was in inverse proportion to their effort. As one man said, "The better your machine, the less you have to do and the more money you get". Since these machines were delicate and complicated, many operators felt that their bonus was largely dependent on the "luck" of breakdowns, for they could not compensate for any loss of running time by putting on a spurt. This led many of them, as also many workers on other types of work, to wish for a daily and not a weekly bonus. As one said, "You learn that you can never say to the wife that you'll work extra hard, say to buy something for the house. You may run into trouble at any time, and you'll never get her to realize that and she'll just think you've been lazy".

The difficulties in seeing a clear relation between effort and reward indicate a serious weakness in bonus schemes in many industrial situations. However, dissatisfaction about the unpredictability of the bonus tended to be more intense on the very jobs in which the relation between personal effort and output seemed to be closest. In the large groups, such as those comprising a whole department of perhaps over 100 workers, the workers accepted the fact that no individual could expect to predict the weekly bonus or to know how far his own work had contributed to it. Most of them, however, felt that this disadvantage was outweighed by the comparative steadiness of a bonus paid on a large group and by the social harmony resulting from the absence of differences in earnings within the department. The small groups, on the other hand, expected to see a direct relation and often thought that this relation was closer and simpler than was in fact the case, and so they experienced disappointment and frustration. The tendency for satisfaction to increase as the size of the group increases is not, of course, incompatible with the findings of research workers, such as Mace
(1935) and Mackworth (1950), who have shown that efficiency of performance is affected by knowledge of results and the ability to measure success in attaining a given target. It suggests that misconceptions about the preciseness and personal nature of the target may lead both to ill-feeling and a weakening of the incentive.

The number of workers who spoke of the complicated method of calculating bonus as a disadvantage of the system was relatively small. However, in reply to a direct question on this point, under a third of the men and only $6.5 \%$ of the women said (sometimes clearly mistakenly) that they thought they understood it. The inability to check the accuracy of the weekly wage was, however, of less importance to most workers than their inability to estimate their daily progress. A few men brought slide rules to the factory and checked to see if their own calculations tallied with those of the wages department, but most workers were content with much simpler methods. One woman, for instance, said, "We compare our pay slips to see if all the groups have got about the same, and if they haven't we ask them to explain why. Not that we're much the wiser for it, but it lets them know we notice." In any case, most workers were, as one said, " no clerks" and found " all these decimals and per cents. just Dutch".

The comments that the timing or rate-fixing were unjust and that the management were unreliable or suspect are somewhat different in character, since they imply criticisms not of the payment system itself but of the ability or intentions of those responsible for devising and administering it. Claims that the "time-study men" gave inadequate allowances for such matters as breakdowns or variations in machines or materials were made, though with varying frequency, in all departments. They were sometimes projections of a dissatisfaction that was not clearly understood, and the " allowances" or the "standards" were blamed because the workers felt strongly that someone or something must be responsible for the insufficiency or variability of their bonus. As one woman said, "When we don't get the bonus we think we should, we sometimes blame the machines or the allowances, sometimes the other girls and sometimes the foreman. It just depends how we feel. But we never really know." In one factory, however, there was a general suspicion that the management deliberately set any new bonus standard too high, so as to allow for bargaining. A worker in this factory said, " Around and around goes the same old circle, 'Too high''Not too high'. Eventually, after months, some compromise is reached. Then production goes sky high to make up for lost bonus, and the management 
think they were right after all." Apart from criticisms of the standards set, there were also some complaints of indirect or direct rate-cutting if a too high output had been reached. In one clothing factory when the output of any line was too high (in relation to other lines) the management " readjusted" the team so as to include in it some less efficient workers. This caused resentment against the management and also social conflict among the women, since the speed of a line was necessarily that of the slowest worker. A group of men tobacco workers alleged an unfair rate-cutting some two years previously and since that time had imposed their own ceiling on production; and several workers in a military equipment department made remarks such as, "If you do too well the overlooker will say something to you, so that you won't have to have your rate cut or be moved."

Although, in the opinion of the investigators, cases of deliberate "twisting" by the time-study engineers were not common in these factories, it should be noted that in no factory was the setting of bonus standards preceded by any thorough and competent motion study. Even the casual observer might notice many examples of inefficient and wasteful methods of working. Some of the workers themselves commented on these and said that they thought it better to continue in these methods than to risk a re-timing of their jobs.

Social Conflicts.-The social conflicts arising from or attributed to the bonus system were in many cases the almost inevitable accompaniment of the various inequalities in opportunity already referred to and most of the comments on conflicts between groups were of this type. The word " conflict" in the sense here used does not necessarily imply personal hostility but rather a sense of division. In a number of cases, workers on the "good" jobs spoke of feelings of discomfort and sometimes almost of shame since their "luck", as they termed it, tended to create a social barrier between them and the less fortunate. One said, " It's especially wrong for me, being a shop steward. I was really much happier when I was on a bad job ". The workers' comments showed that their wish for social harmony and for justice was sometimes frustrated by circumstances resulting from the system of payment, and, in other cases, that it came into conflict with the individual's desire or need to earn as much as he could irrespective of whether his rewards were due to merit or to chance. A small proportion of both men and women spoke of definitely hostile competitiveness between groups, particularly where a number of small groups were all engaged on similar work. In one such department in a tobacco factory the workers themselves had attempted to prevent this jealousy by refusing to agree to the production study engineer's proposal to post up the weekly output of each machine, and they had created a social code by which it was " not done " to try and discover another man's earnings.* Despite this, envy and jealousy existed and men watched their neighbours. There were sometimes open quarrels but envy was not always entirely of money, which might also be important as a symbol of superior skill or personal worth. As one man said, "If I'm having trouble with my machine and I see the man on the next machine doing well I can't help thinking ' He's a better man than me' even if I know he isn't." Among these machine operators there was a strong wish to have their bonus system abolished, but the management firmly refused to do this, fearing a big drop in output. One of the men remarked, "You see, the management don't trust us to do a fair day's work, even though most of us have been here for years. They think we won't do anything except for money, and they're not interested in us but only in what we turn out." This feeling probably contributed towards making the poorer or less fortunate workers consider themselves personally inferior, but in this department as elsewhere there were some whose wish for dominance and superiority was given a means of expression if not positively encouraged through the system of payment.

Conflict within the groups arose mainly from differences between individuals in their willingness or capacity to work. Proportionately more women than men complained of laziness in others in the team, though it seemed that in some cases the word " lazy" was used by girls to describe someone whom they disliked for general or quite other reasons. In some groups of women the desire to earn bonus was often and apparently easily defeated by purely social motives. For instance, on one line in a clothing factory some girls admitted that they did not try to reach their target because they disliked their woman overlooker and "you don't feel like working if they (i.e. the supervisors) don't care." On another line one girl said that she had "said something to upset some of the girls" and so they had interfered with her machine. She added, "I've been off work for a week and it's only through worrying about the girls." Since the jobs on the line were interdependent any breakdown affected the whole team, but apparently the satisfaction of revenge was greater than that of money. The

* A similar code, most rigidly adhered to, existed in a social group of women individual piece workers in another tobacco factory. 
comments on differences in capacity to work, although not very numerous, were often very emphatic. Resentment against the older, less fit or less competent members of a group was not common although many workers stressed the importance of having a homogeneous team, both personally and in capacity. Some workers, both men and women, considered that the social disunity caused by the bonus system was its greatest disadvantage and went so far as to say that, on this account alone, it was " evil " and produced " tragic results" and had "made more enemies than time can tell ".

Personal Conflicts.-The comments grouped under the heading of "personal conflicts" are those in which the individual considers the bonus system purely in its effects on his own attitude of mind or health of body. Complaints that the bonus led to feelings of strain or exhaustion were made by $19.2 \%$ of men and $11.4 \%$ of women. Comments on physical fatigue came mainly from workers in certain tobacco departments, in which conditions were hot and humid, and from the men making prefabricated houses. In the former case the complaints were often accompanied by expressions of anxiety that increasing age would soon make the present speed of working impossible. In the latter a number of the men were already 60 years old or more and felt driven too hard by the speed set by the group and, as one said, " by being determined not to let them say that we are on their backs".

Nervous strain, rather than physical fatigue, was experienced by some of the machine workers. One of them said, "The strain is hard to explain to a lay person. The machines are almost human in their cussedness, and the strain is all increased by the bonus system, which accounts for $75 \%$ of it. The only thing to like about the bonus system is the money. Apart from that I hate the sight of it. It makes you a slave to the machine and the allowances are not adequate or fair." Another man, on a different type of machine, said, "It's the ruin of men's health, physically and mentally. When the bonus came on I worked so hard that I got pleurisy, with the sweating and then catching cold. Since then I've not bothered, for health is more important. At the moment I'm washing walls down, not on bonus, and have a nice relaxation of mind. They've a dozen or so of us employed on this and they're all cheerful and singing. It's because they're not on a bonus machine, though they don't realize it themselves." Another, aged 31, said, "In a few more years I shan't be able to keep at the rate needed. I don't know how some of the older chaps manage, because when I go home I'm finished. I flop in a chair and have no energy to lead my own life."

It is, of course, possible to argue, as did the timestudy engineer of some of the workers quoted, that such comments indicate the "success" of the incentive. However, apart from the question as to whether this might not be a short-sighted point of view, there can be little doubt that some workers suffered severely from what they termed " nervous tension" and were apprehensive of becoming unable to continue their present jobs. Such workers often made the task of supervision difficult, one departmental manager describing his machine operators as "extraordinarily difficult to handle, touchy and liable to flare up over any trifle ", while another manager said that three-quarters of his time was spent in dealing with complaints about the bonus system.

The most frequent comment under the heading of conflict with " own code of behaviour" referred to the struggle between the desire for speed and the desire for quality. Quite apart from the effect that " rejects" had in lowering the bonus, the turning out of work that was not as good as it might have been was disliked and resented by some workers. On some of the jobs the product went through the hands of examiners before being passed on for the next process but in others the workers themselves acted as examiners. In the latter case workers sometimes gave way to the temptation to pass work that was of doubtful quality, especially if faults might plausibly be attributed to poor materials, although they might feel guilty in doing so. In the military equipment departments some workers admitted to breaking the safety regulations and others were very emphatic that it was "all wrong" to tempt them to take risks with articles which might be dangerous to the users as well as to the makers.

Various devices were used in the factories investigated to prevent the workers from working at a speed likely to prove deleterious to quality. One worker described his management as " trying to have it both ways and always dissatisfied because they won't realize that this is impossible". These devices, however, often failed to take effect because the workers did not understand them. For example, on a group of machines in a cigarette factory, the management set a ceiling on daily production and stated that output in excess of this was not to be counted for bonus payment. The women resented this ceiling on the grounds that "I always thought the idea of a bonus system was that you could earn as much as you like" and also because they found it 
extremely difficult to know when they had reached the prescribed limit and so often did more work than they were paid for.

The comments made by a few workers that bonus was " against Trade Union principles" referred to the traditional objections that payment by results led to unemployment and to exploitation. In some of these, and also in some of the remarks about the bad effects of bonus on character, the objections were primarily on ethical grounds. While it is true that what might be termed moral judgments were implied also in many of the remarks previously discussed about the injustice or enmity caused, here they were explicit and were expressed in phrases such as, "It makes you hard when you would not be normally. It brings out the worst in you ", "It sets men against each other and is an evil thing ", and, "It encourages you to be too kind to yourself when you are booking your stoppages".

\section{Summary}

Some results of an investigation into the attitudes of 386 men and 402 women towards group bonus methods of payment are described. The workers' self-assessments of their general attitude to this system of payment showed that about two-thirds of the total number were either definitely dissatisfied with it or were neutral or divided in opinion. Although proportions varied in different types of work, in only one group did as many as half the workers express themselves as satisfied. The main reasons given for liking the system were that it increased earnings, many workers saying that without it they would not earn a living wage, and that group payment had various social advantages. About $80 \%$ of the workers made some criticism of the system and the criticisms indicate that the workers tended to have very similar standards of judgment, despite the great differences in their jobs and circumstances.

An analysis of the reasons given for disliking the system shows that it aroused three main types of psychological conflict. First, the desire to earn more money, stimulated by the assumption that reward is dependent on effort, is often thwarted both by the difficulty of observing the relationship and by the influence on the bonus of many factors outside the control of the worker. This leads to a sense of injustice, which may be expressed in aggressive behaviour or in feelings of helplessness.
Secondly, and closely connected, are the social conflicts arising within or between the payment groups. Thirdly, workers may experience personal conflicts in that they feel impelled to act in a way that is opposed to their concern for their health, their standards of workmanship, or their ethical code.

These conflicts are basically psychological and are largely emotional rather than intellectual in nature. They tend to arise when bonus systems are introduced in unsuitable circumstances and without due knowledge of or regard for the existing motives and scale of values of the workers.

There is considerable evidence that these systems of payment cause feelings of physical and, more often, mental strain. Complaints of strain are apparently seldom referred to the factory medical officer, either because workers consider that conditions of payment, unlike physical working conditions, are outside his sphere or because they fear he might order them to be moved to a job which carries no bonus and which they cannot afford.

The factories here investigated all employed medical officers and had well equipped surgeries and welfare departments. In no case did the medical officer take any part in advising on the systems of payment, which were usually left entirely to the production study engineers. These engineers tended to base their theories and practices on inadequate and often wholly unwarranted psychological assumptions about " the worker". It is suggested that there is urgent need for systems of payment to be regarded primarily as matters affecting the health and morale of workers and, therefore, in their broad principles, as the concern of the industrial medical officer. Many of the objections raised to them might be obviated if the general policy were jointly framed by management, personnel officers, and medical officers, and if the production engineers were regarded as technical experts to carry out this policy. The effects of systems of payment present an almost unexplored field for students both of social psychology and social medicine.

\section{REFERENCES}

International Labour Office (1951). Payment by Results (Studies and Reports, No. 27.) pp. 178, 179. Geneva.

Lane, R. E. (1936). Lancet. 2, 206.

Ministry of Labour Gazette (1952). 60, 121

Ministry of Labour and National Service (1951). Wage Incentive Schemes, Industr. Rel. Handbook Supp. No. 4, pp 216 H.M.S.O. London.

Mace, C. A. (1935). Rep. industr. Hlth. Res. Bd., Lond., No 72.

Mackworth, N. H. (1950). Spec Rep. Ser. med. Res. Coun., (Lond.) No. 268. H.M.S.O. London. 